\title{
Esophageal Spindle Cell Carcinoma
}

National Cancer Institute

\section{Source}

National Cancer Institute. Esophageal Spindle Cell Carcinoma. NCI Thesaurus. Code C95608.

An esophageal squamous cell carcinoma characterized by the presence of a spindle-cell carcinomatous component. Crossly it has a polypoid appearance and usually arises from the middle or lower third of the esophagus. 